\title{
On crystallisation and fracture toughness of poly(phenylene sulphide) under tape placement conditions
}

\author{
W. J. B. Grouve ${ }^{* 1}$, G. Vanden Poel ${ }^{2}$, L. L. Warnet ${ }^{1}$ and R. Akkerman ${ }^{1}$
}

Fibre reinforced thermoplastic tapes are subjected to high heating and cooling rates during the tape placement process. Such high cooling rates can significantly inhibit the crystallisation of the thermoplastic polymer and thereby affect its mechanical properties, such as strength or toughness. In the present work, the crystallisation of poly(phenylene sulphide) (PPS) subjected to high cooling rates was investigated using a fast scanning calorimeter. The PPS was found to be unable to crystallise when subjected to cooling rates higher than $20^{\circ} \mathrm{C} \mathrm{s}^{-1}$. The influence of the degree of crystallinity on fracture toughness was investigated using an essential work of fracture approach. The amount of plastic work during the fracture process was found to decrease after moderate annealing.

Keywords: Thermoplastic composites, Tape placement, Crystallisation, Fracture toughness

\section{Introduction}

\section{Background and motivation}

The laser assisted tape placement process, schematically illustrated in Fig. 1, is a promising manufacturing technique for thermoplastic composites, combining in situ consolidation with high productivity. ${ }^{1}$ Unidirectionally (UD) fibre reinforced thermoplastic tapes can be deposited at high rates onto a pre-consolidated (in some cases double curved) laminate. This laminate can be produced by either the tape placement process itself or by an alternative, more conventional, manufacturing technique. The mechanical properties of the final component can be tailored to a high degree by incrementally placing the tapes in the desired orientation. The process shows great potential for automation, which makes it attractive for the aerospace or automotive manufacturing industries. Moreover, the tapes can potentially be welded in situ, that is without an energy consuming consolidation step in an autoclave. ${ }^{1}$ Currently, however, such a post-consolidation step is still required in order to obtain the desired mechanical properties. Much effort is spent optimising the process in order to omit this expensive step and reach truly in situ tape placement. Such an optimisation procedure requires a thorough understanding of the interrelation between processing parameters, constituent material properties and final component performance.

The characteristic process time, i.e. the time available for consolidation, is extremely short for the tape placement process. Such short process times can only

${ }^{1}$ Faculty of Engineering Technology, University of Twente, Drienerlolaan 5, 7500AE Enschede, The Netherlands

${ }^{2}$ DSM Resolve, Geleen, The Netherlands

*Corresponding author, email w.j.b.grouve@utwente.nl be achieved when the material is subjected to extremely high heating and cooling rates, 2,3 which can easily exceed $400^{\circ} \mathrm{C} \mathrm{s}^{-1}$. In the case of semicrystalline polymers, these high rates can significantly influence the resulting degree of crystallinity of the matrix material, and thereby the final product properties. The emergence of these fast manufacturing processes calls for an improved understanding of the crystallisation under highly non-isothermal conditions. Moreover, the influence of the degree of crystallinity on the material properties also becomes of increased interest.

The present work focuses on poly(phenylene sulphide) (PPS), which is a thermoplastic used in composite structures for aerospace applications. Earlier work by Grouve et $\mathrm{al}^{4}{ }^{4}$ focused on the tape placement of UD carbon reinforced PPS tapes onto woven fabric reinforced PPS laminates. It was shown that the UD carbon-PPS tapes exhibited a very low degree of crystallinity after tape placement. Apparently, the high cooling rates prevented the PPS in the tape from crystallising. Mandrel peel experiments demonstrated that these tape placed specimens exhibited a very high interfacial fracture toughness compared to press moulded (and slowly cooled) specimens. This difference was partly attributed to the low degree of crystallinity of the PPS in the tape, making it more susceptible to dissipate energy through plastic deformation during the fracture process. The present work aims to support these observations and investigates the crystallisation and fracture behaviour of neat PPS under tape placement conditions.

\section{Literature overview}

The isothermal ${ }^{5-7}$ and non-isothermal ${ }^{8,9}$ crystallisation kinetics of PPS have been investigated thoroughly in the literature. The literature reviews of Lopez and Wilkes ${ }^{10}$ 


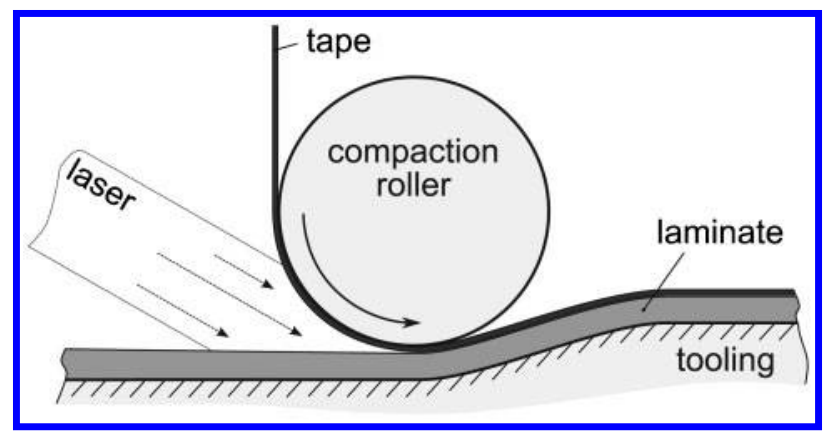

1 Schematic illustration of laser assisted tape placement process

and Cebe ${ }^{11}$ provide a comprehensive overview of the earlier work. Despite the abundance of literature on this topic, little work has been performed on the crystallisation of PPS under highly non-isothermal conditions. The present work employs fast scanning calorimetry (FSC) to investigate at which rate the PPS is unable to crystallise. The results aim to support the earlier experimental observations ${ }^{4}$ that the carbon-PPS tapes cannot crystallise during the tape placement process.

Spruiell and Janke ${ }^{12}$ provide a comprehensive overview of the research on the effect of crystallinity and morphology on the mechanical properties of neat and fibre reinforced PPS. The tensile modulus and strength are, for the high molecular weight PPS used in composites, found to increase with an increasing degree of crystallinity. The fracture toughness of PPS and its composites, however, has not been researched extensively. Davies et $a l^{13}$ investigated the influence of crystallinity on fracture toughness of PPS based composites and showed that the mode I and mode II fracture toughness of carbon-PPS composites slightly decrease with increasing crystallinity. A similar observation was made by Nishihata et al. ${ }^{14}$. Nevertheless, there is, to the best of the authors' knowledge, not much literature available on the influence of the degree of crystallinity on the fracture toughness of neat PPS. The present work, therefore, investigates the fracture toughness of as received (low degree of crystallinity) and annealed PPS film using the essential work of fracture (EWF) approach.

\section{Objective and outline}

The present work investigates the crystallinity and fracture behaviour of PPS that has been subjected to high cooling rates. For this purpose, the work is divided into three coherent parts. First, the critical cooling rate is determined at which PPS is still able to crystallise. The experiments are performed using a, recently introduced, fast scanning calorimeter from Mettler-Toledo: the Flash DSC 1. The experiments aim to confirm whether the PPS in the tape is indeed unable to crystallise under typical tape placement conditions. Second, tensile tests are performed on as received (low degree of crystallinity) and annealed PPS film to study the effect of crystallinity on the tensile properties. These tests provide qualitative information concerning the amount of plastic deformation during failure. Finally, the effect of crystallinity on the fracture properties is investigated quantitatively using a fracture mechanics approach. The present work employs the EWF approach. The EWF method can be used to quantify the fracture toughness for materials which show significant crack tip plasticity, when the linear elastic fracture mechanics approach becomes invalid.

The next section introduces the experimental work, which comprises FSC and mechanical testing. Subsequently, the experimental results are presented, followed by a discussion. Finally, the conclusions are presented.

\section{Experimental}

The material under consideration is PPS film known as Fortron 0214 from Ticona. The PPS has a glass transition temperature and melting temperature of 85 and $285^{\circ} \mathrm{C}$ respectively, according to the data from the manufacturer. The calorimetry experiments and tensile tests were performed on film with a thickness of $160 \mu \mathrm{m}$, while the EWF experiments were performed on film having a thickness of $60 \mu \mathrm{m}$. The mechanical tests were performed on both as received and annealed film specimens. The degree of crystallinity $\chi_{c}$ of the samples was measured using a standard differential scanning calorimeter from Mettler-Toledo (DSC 822) under inert atmosphere. These specimens were heated with a rate of $10^{\circ} \mathrm{C} \mathrm{min} \mathrm{min}^{-1}$ to a temperature of $330^{\circ} \mathrm{C}$. The mass fraction of the crystalline region is then given by

$$
\chi_{\mathrm{c}}=\frac{\Delta H_{\mathrm{f}}+\Delta H_{\mathrm{c}}}{\Delta H_{\mathrm{f}}^{0}}
$$

in which $\Delta H_{\mathrm{f}}$ and $\Delta H_{\mathrm{c}}$ are the measured value of the melting enthalpy and the energy associated with the cold crystallisation exotherm respectively. By convention, $\Delta H_{\mathrm{f}}$ is positive and $\Delta H_{\mathrm{c}}$ is negative. The value for $\Delta H_{\mathrm{f}}^{0}$ represents the melting enthalpy of PPS with $100 \%$ crystallinity and equals $150 \cdot 4 \mathrm{~J} \mathrm{~g}^{-1}$, based on the data provided by Spruiell and Janke. ${ }^{12}$

\section{Critical quench rate}

The investigation of the crystallisation of PPS under tape placement conditions requires FSC. In the present work, an FSC based on microelectromechanical system technology is applied: the Flash DSC 1 from MettlerToledo, which was released by the end of $2010 .{ }^{15-18}$ Recently, it has been elaborately investigated for its performance and for finding and defining the calibration protocols required for reliable results and adequate interpretation of the data generated. ${ }^{19}$ The Flash DSC 1 equipment was kindly made available at DSM Resolve laboratory.

The Flash DSC 1 does not measure samples in crucible, because the heat capacity and thermal conductivity of the pan would have a significant influence on the end results. Instead, the sample is placed directly onto a chip, which allows measurements under extremely high heating and cooling rates ${ }^{16}$ of more than $20000^{\circ} \mathrm{C} \mathrm{s}^{-1}$. A small specimen, in the order of $500 \mathrm{ng}$, was cut from the as received PPS. The specimen was loaded in the Flash DSC 1, melted down in order to stick on the sensor and cooled from 350 to $-50^{\circ} \mathrm{C}$ with a cooling rate varying from 1 to $5000^{\circ} \mathrm{C} \mathrm{s}^{-1}$. Subsequently, the specimen was heated with a scan rate of $100^{\circ} \mathrm{C} \mathrm{s}^{-1}$, which was high enough to prevent cold crystallisation (i.e. crystallisation during heating) during the heating scan. The data was evaluated with the StarE software version 10 of Mettler-Toledo. The subsequent heating curves after cooling at a specific rate are monitored to observe whether or not a melting peak 


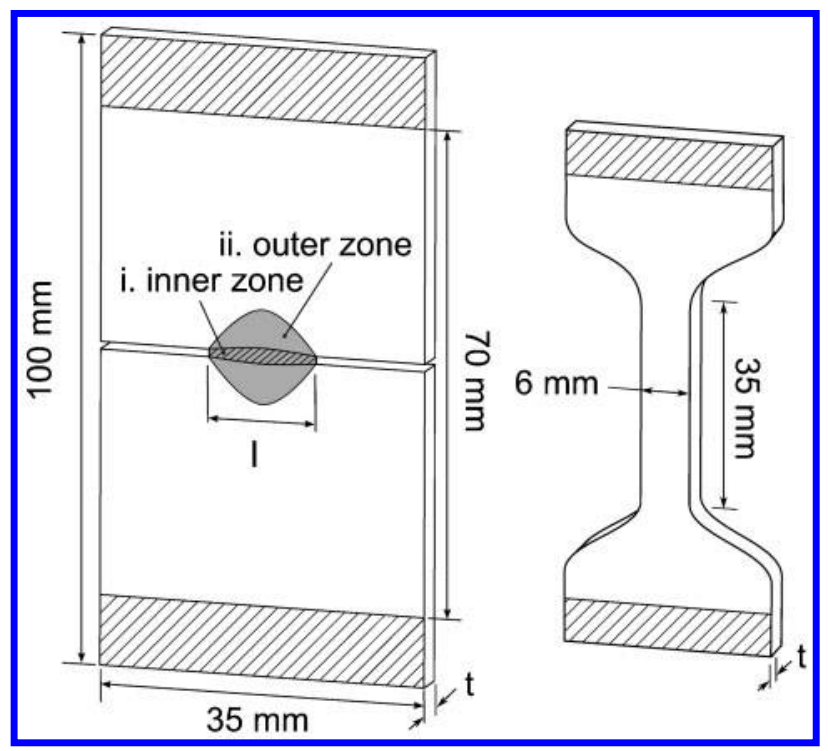

2 PPS film test specimen dimensions (hatching represents clamped part). Left: notched specimen for EWF experiments showing fracture zones (i. inner fracture process zone; ii. outer plastic deformation zone). Right: dumbbell specimen for tensile tests

can be identified. The presence of a melting peak points that the PPS was able to crystallise on the preceding cooling run.

\section{Tensile properties}

Tensile tests were performed on dumbbell shaped PPS film specimens having a thickness of $160 \pm 2 \mu \mathrm{m}$. The gauge width and length, as shown in Fig. 2(right), were 6 and $35 \mathrm{~mm}$ respectively. All specimens were cut using a manual die cutting machine with their length oriented parallel to the roll direction. A total of 12 specimens were produced of which six were annealed in an oven at $130^{\circ} \mathrm{C}$ for $30 \mathrm{~min}$. The DSC showed that the as received film had a crystallinity $\chi_{c}$ of $5 \cdot 5 \%$, while for the annealed specimens a degree of crystallinity of approximately $24 \%$ was found. The specimens were loaded in a universal testing machine fitted with a $1 \mathrm{kN}$ force cell and Zwick sensor arm extensometer. Furthermore, the specimens were marked every $5 \mathrm{~mm}$ to provide an estimate of the local strain in the necking area after testing. The crosshead displacement rate equalled $0.5 \mathrm{~mm} \mathrm{~min}^{-1}$ for all specimens.

\section{Fracture toughness Background}

The EWF method allows the fracture characterisation of ductile polymers for which the linear elastic fracture mechanics approach is invalid. The foundation of the EWF approach was laid down by Broberg $^{20}$ who proposed that the region near the crack tip may be divided into two zones: i. an inner fracture process zone and ii. an outer plastic deformation zone. Figure 2(left) shows the specimen and illustrates these process zones. The work in the inner fracture process zone comprises the energy required to create new surfaces and includes the necking and subsequent tearing of the ligament. The work in the outer plastic deformation process zone comprises various deformation mechanisms such as shear yielding or microvoiding. ${ }^{21}$ The total work of fracture $W_{\mathrm{f}}$, calculated from the area under a forcedisplacement curve, can now be partitioned into two terms

$$
W_{\mathrm{f}}=W_{\mathrm{e}}+W_{\mathrm{p}}
$$

The EWF $W_{\mathrm{e}}$ represents the work expended in the inner fracture process zone and is assumed to be proportional to the ligament length $\ell$. The non-EWF $W_{\mathrm{p}}$ represents the work spent in the outer plastic deformation zone and is assumed to be proportional to the squared ligament length

$$
W_{\mathrm{f}}=w_{\mathrm{e}} t \ell+w_{\mathrm{p}} \beta t \ell^{2}
$$

in which $t$ represents the film thickness and $\beta$ represents a shape factor. Normalising equation (3) with respect to $t \ell$ yields the specific total work of fracture $w_{\mathrm{f}}$

$$
w_{\mathrm{f}}=w_{\mathrm{e}}+w_{\mathrm{p}} \beta \ell
$$

The specific EWF $w_{\mathrm{e}}$ is now determined as the $y$ intercept of a linear least square fit of $w_{\mathrm{f}}$ versus $\ell$ data, while the slope of the fit gives the value for $\beta w_{\mathrm{p}}$ which is known as the specific non-EWF. The specific EWF $w_{\mathrm{e}}$ is considered a material parameter for a given sheet thickness, independent of specimen geometry. ${ }^{22,23}$ The non-EWF $\beta w_{\mathrm{p}}$ measures the amount of plastic deformation around the crack tip and is not regarded as a material property but depends on the specimen geometry.

The experimental procedure reduces to obtain the total work of fracture $W_{\mathrm{f}}$ from the area under the forcedisplacement curves of film specimens with different ligament lengths. ${ }^{24,25}$ The simplicity of this procedure is one of the major reasons for the increasing popularity of the EWF method. The method has been applied to a number of different polymers of which the recent review work by Bárány et al. ${ }^{25}$ gives a broad overview. The influence of crystallinity (or rather an annealing procedure) on the specific essential $w_{\mathrm{e}}$ and specific non-essential $\beta w_{\mathrm{p}}$ work of fracture has been investigated for a few thermoplastics, such as $\mathrm{LDPE}^{26}$ and PP. ${ }^{27}$ Generally, it can be said that an increase in crystallinity results in an increase of $w_{\mathrm{e}}$, but reduces $\beta w_{\mathrm{p}}{ }^{25}$ However, to the best of the authors' knowledge, no results have been published on EWF on PPS.

\section{Experimental procedure}

The procedure followed for the EWF experiments was based on the latest ESIS TC4 protocol. ${ }^{28}$ The specimens were cut from the PPS film using a sharp scalpel. They had a thickness of approximately $60 \pm 2 \mu \mathrm{m}$ and width and length of 35 and $100 \mathrm{~mm}$ respectively. The length between the clamps equalled $70 \mathrm{~mm}$, as is also shown in Fig. 2(left). The notches were applied by sliding a sharp razor blade through the notches of a steel template. A total of four templates were used, having ligament lengths of nominally 3, 4, 6 and $8 \mathrm{~mm}$. A new razor blade was used for every specimen. The final ligament length $\ell$ was measured using a travelling microscope and the thickness of the film at the ligament was measured using a film thickness gauge with a resolution of $0.5 \mu \mathrm{m}$. At least five specimens were tested for each steel template.

The tests were performed on as received film and on annealed film. A few specimens were subjected to the annealing procedure followed for the tensile specimens, i.e. these were annealed at $130^{\circ} \mathrm{C}$ for $30 \mathrm{~min}$. The majority of the specimens, however, were annealed at a 


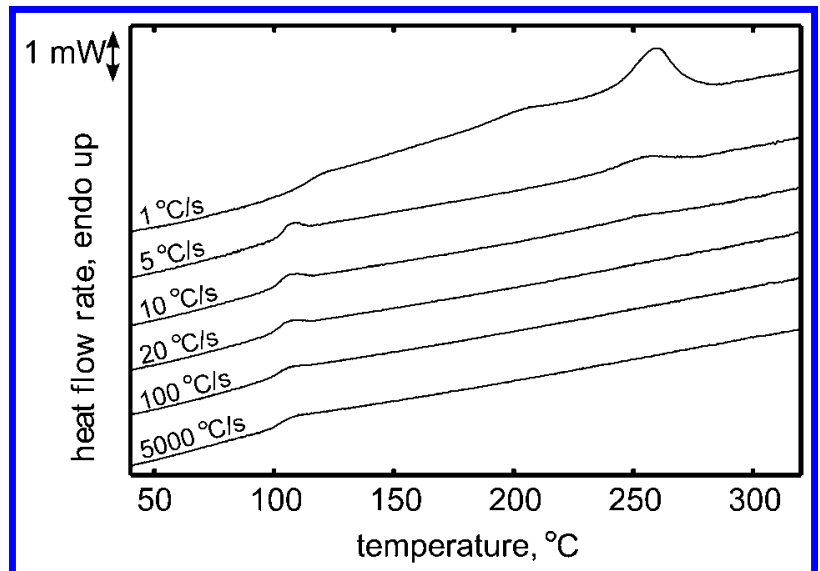

3 Subsequent Flash DSC heating curves of PPS (scan rate $=100^{\circ} \mathrm{C} \mathrm{s}^{-1}$ ) after cooling at rates from 1 to $5000^{\circ} \mathrm{C} \mathrm{s}^{-1}$

lower temperature of $120^{\circ} \mathrm{C}$ and for a shorter time period of $15 \mathrm{~min}$. A DSC measurement showed that these annealed $\left(120^{\circ} \mathrm{C}\right)$ specimens had a degree of crystallinity of approximately $17 \%$, compared to $28 \%$ for the specimens annealed for $30 \mathrm{~min}$ at $130^{\circ} \mathrm{C}$. The EWF specimens were loaded in a universal testing machine fitted with a Zwick $100 \mathrm{~N}$ force cell. The crosshead displacement was measured using a displacement transducer with a resolution of $1 \mu \mathrm{m}$. The crosshead displacement rate equalled $0.5 \mathrm{~mm} \mathrm{~min}^{-1}$.

\section{Results}

\section{Critical quench rate}

The critical quench rate was determined by subjecting PPS to various cooling rates (from 1 up to $5000^{\circ} \mathrm{C} \mathrm{s}^{-1}$ ) and one particular heating rate, which presents melting only (in all cases absence of crystallisation upon heating, which is usually called cold crystallisation). Figure 3 represents the Flash DSC 1 heating curves of the PPS specimen. The PPS sample was heated in all cases from -50 to $350^{\circ} \mathrm{C}$ with a scan rate of $100^{\circ} \mathrm{C} \mathrm{s}^{-1}$. The trace corresponding to a cooling rate of $1^{\circ} \mathrm{C} \mathrm{s}^{-1}$ clearly shows an endothermic peak near $275^{\circ} \mathrm{C}$, which represents the melting of the crystalline structure created under these cooling conditions. The peak demonstrates that the PPS specimen was able to crystallise during the preceding cooling run. Similar, though smaller, peaks are observed when the PPS was cooled with rates of 5 and $10^{\circ} \mathrm{C} \mathrm{s}^{-1}$. Nevertheless, when cooled at a rate of $20^{\circ} \mathrm{C} \mathrm{s}^{-1}$, the subsequent heating trace does not show any endothermic peak signal, from which can be interpreted that no melting occurs. Apparently, the PPS is unable to crystallise at scan rates of $20^{\circ} \mathrm{C} \mathrm{s}^{-1}$ or higher. The subsequent heating curves after respectively 100 and even $5000^{\circ} \mathrm{C} \mathrm{s}^{-1}$ of cooling are similar if not equal to the one for cooling at $20^{\circ} \mathrm{C} \mathrm{s}^{-1}$.

Firmly, one can state that this type of PPS is fully quenched, and hence is completely amorphous, at cooling rates above $20^{\circ} \mathrm{C} \mathrm{s}^{-1}$. This scan rate is far from the real processing cooling rate. Typically, a fibre reinforced thermoplastic tape can be subjected to cooling rates in excess of $400^{\circ} \mathrm{C} \mathrm{s}^{-1}$ during the tape placement process. This means that during the processing of PPS tapes the polymer is unable to crystallise. Discussions are at present going on how large the contribution of the influence of shear and/or flow is on

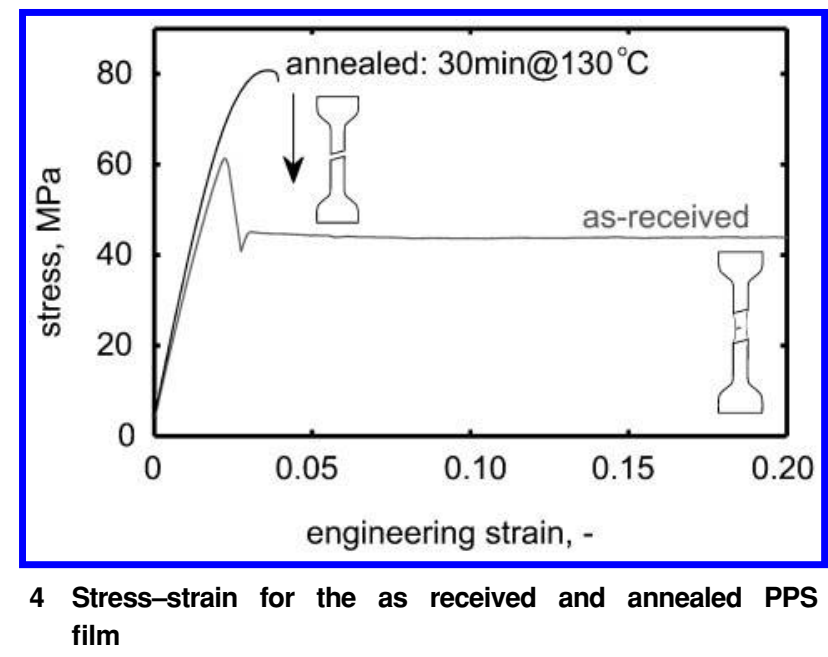

the quench rate (typically shear/flow will increase the crystallisation rate not more than 10 times). Even if one argues that shear/flow induced crystallisation can take place during this process, the difference with the quench rate as defined by FSC and the processing cooling rate is that large (about 20 times higher) that one can firmly conclude the PPS film remains amorphous during processing. As a result, the properties, such as chemical resistance or fracture toughness, of the resulting structure might differ from structures manufactured using more conventional, and slower, production processes.

\section{Tensile properties}

Figure 4 shows a typical stress-strain curve for an as received and an annealed PPS dumbbell specimen. The graph shows a significant change in tensile behaviour upon crystallisation. The as received specimens showed necking followed by an extensive period of cold drawing before failure, while the annealed specimens failed in a more brittle manner.

Table 1 summarises the obtained experimental results. The tensile modulus and the maximum stress increased after annealing, while the maximum strain at failure decreased significantly as shown in Fig. 4. The maximum strain listed in Table 1 concerns the global strain as measured by the extensometer. Locally, the strain could exceed $250 \%$ as determined by measuring the length change between the markings on the specimens. All as received specimens failed before the full ligament length yielded, which was attributed to impurities and local thickness variations in the film.

\section{Fracture toughness}

Figure 5 shows the force-displacement curve for an as received and an annealed EFW specimen. The specimen shown here was annealed for $30 \mathrm{~min}$ at $130^{\circ} \mathrm{C}$. The graph clearly shows that this specimen failed in a brittle manner and showed no yielding and tearing prior to failure, thereby rendering the EWF approach inapplicable. The specimens annealed at $120^{\circ} \mathrm{C}$ for $15 \mathrm{~min}$, however, did show full ligament yielding prior to failure. The EWF analysis is, therefore, applied on these as well as the as received specimens. Figure 6 and 7 show typical force-displacement curves for the as received and annealed $\left(120^{\circ} \mathrm{C}\right)$ specimens respectively. All specimens, except the annealed specimens with a ligament length $\ell$ larger than $6 \mathrm{~mm}$, underwent full ligament yielding prior 


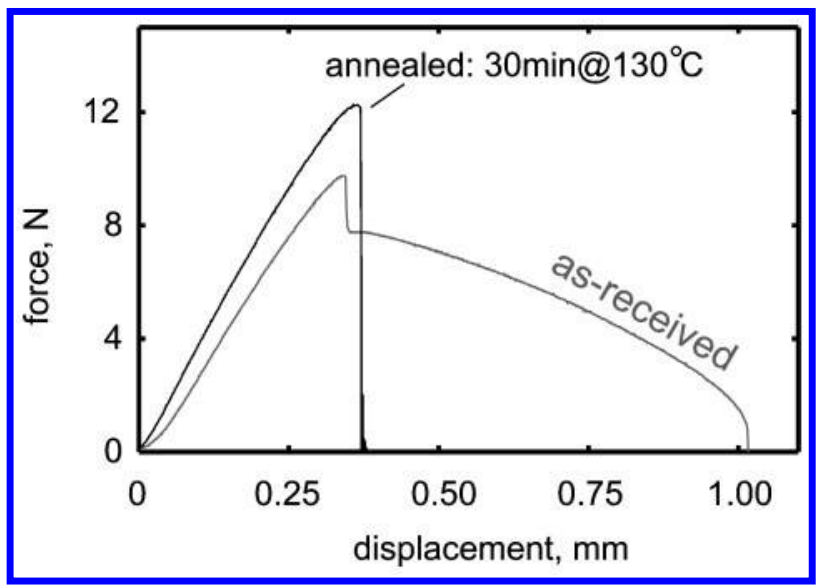

5 Force-displacement curve for as received EWF specimen $(\ell=2.64 \mathrm{~mm})$ and annealed, at $130^{\circ} \mathrm{C}$ for $30 \mathrm{~min}$, EWF specimen $(\ell=2.63 \mathrm{~mm})$

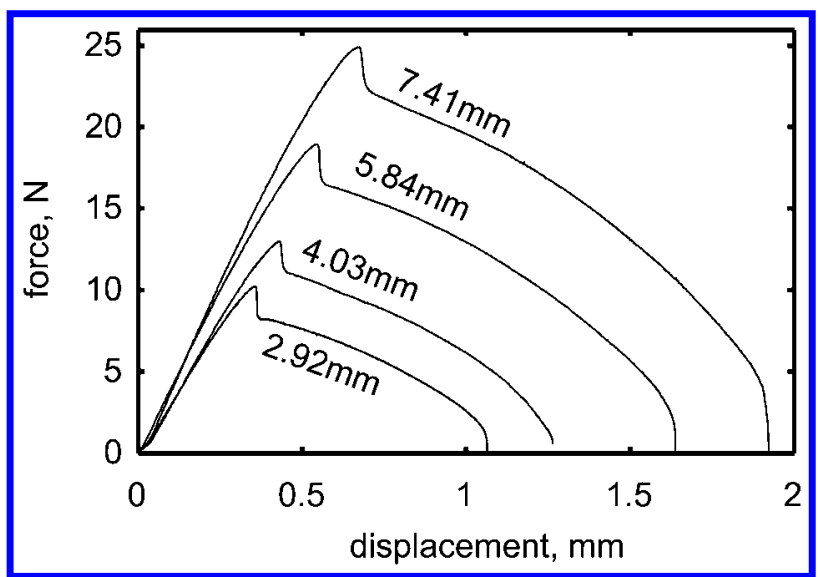

6 EWF force-displacement traces for as received PPS film specimens

to final fracture. A basic requirement for applying the EWF approach is a geometrical similarity of the curves for varying ligament lengths. The graphs show that this is clearly the case. Furthermore, it can be seen that annealing reduces the extension at failure, but increases the maximum force. The tensile tests, presented earlier, showed a similar trend.

Figure 8 shows the calculated maximum stress for all tested specimens. The grey areas represent the stress criterion given in the ESIS TC4 protocol. ${ }^{28}$ This criterion states that any essential work data for which the maximum stress is greater than $1 \cdot 1 \sigma_{\mathrm{m}}$ or less than $0 \cdot 9 \sigma_{\mathrm{m}}$ should be rejected, in which $\sigma_{\mathrm{m}}$ represents the average value of the maximum stress

$$
\sigma_{\mathrm{m}}=\frac{F_{\max }}{t \ell}
$$

with $F_{\max }$ the maximum measured force. The graph shows that the data used in the present work fulfill this criterion.

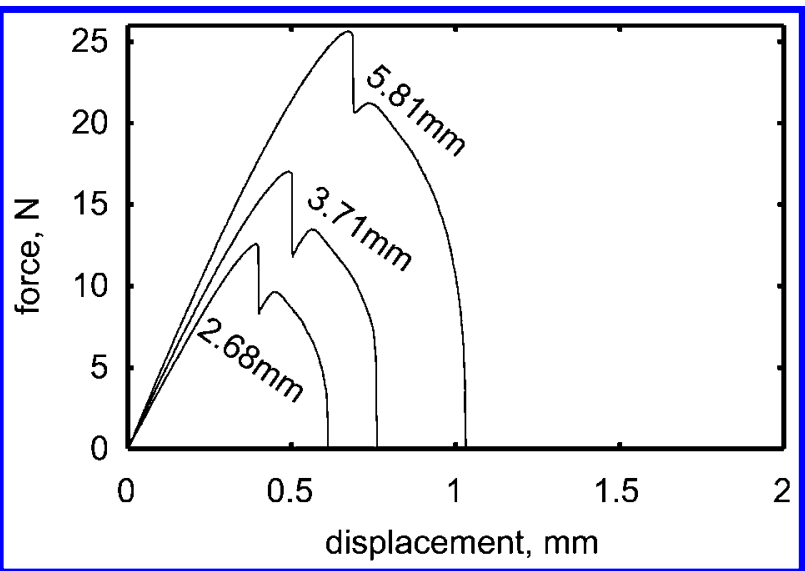

7 EWF force-displacement traces for annealed (15 min, $\left.120^{\circ} \mathrm{C}\right)$ PPS film specimens

Figure 9 shows the specific work of fracture $w_{\mathrm{f}}$ as a function of ligament length $\ell$ for the as received and annealed specimens. The figure shows a linear relation between $w_{\mathrm{f}}$ and $\ell$ for both samples, although it must be pointed out that only three distinct ligament lengths were used for the annealed sample. A linear fit of the data demonstrates that the EWF $w_{\mathrm{e}}$ is not affected by the annealing procedure. According to the literature, however, annealing often results in an increase in $w_{\mathrm{e}}$. The chosen moderate annealing procedure (15 min, $120^{\circ} \mathrm{C}$ ) might not have any distinctive effect on the EWF. The change in slope of the linear fit $\beta w_{\mathrm{p}}$, however, does indicate that annealing decreases the amount of plastic work during failure.

\section{Discussion}

The previous experiments focused on the crystallisation and fracture behaviour of PPS under tape placement conditions. Fast scanning calorimetry experiments showed that the PPS, considered in this work, is unable to crystallise when subjected to cooling rates larger than $20^{\circ} \mathrm{C} \mathrm{s}^{-1}$, which is significantly lower than the rate typically observed during tape placement. Based on these data, tape placed PPS composites will exhibit a low degree of crystallinity, as was also demonstrated in an earlier study. ${ }^{4}$ It must be pointed out here, however, that the crystallisation was investigated under quiescent conditions. There is a limited amount of literature available concerning the shear induced crystallisation of $\mathrm{PPS},{ }^{29}$ and additional research in this subject is desired.

The effect of the degree crystallinity on the toughness was investigated using the EWF approach. Although the as received (low crystallinity) specimens showed a higher specific work of fracture $w_{\mathrm{f}}$ than the annealed specimens, the specific EWF $w_{\mathrm{e}}$ was approximately equal for both samples. Apparently, the short annealing time at a relatively low temperature did not result in a distinctive change in the amount of energy required to create new

Table 1 Averaged data from tensile tests on as received and annealed $\left(30 \mathrm{~min}, 130^{\circ} \mathrm{C}\right)$ PPS dumbbell specimens*

\begin{tabular}{lclll}
\hline Sample & Crystallinity/\% & Tensile modulus/GPa & Max. stress/MPa \\
\hline As received & 5 & $2.91(0.04)$ & $61 \cdot 67(1 \cdot 10)$ & $19(12)$ \\
Annealed & 24 & $3.32(0.06)$ & $81 \cdot 86(1 \cdot 22)$ & $4(0.09)$ \\
\hline
\end{tabular}

*The data between brackets represent the standard deviation. 


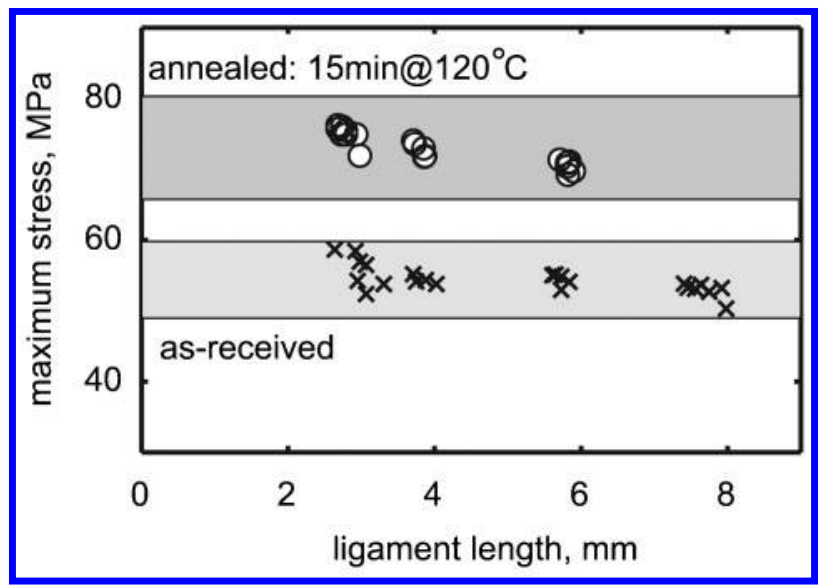

8 Maximum stress for as received and annealed ( $15 \mathrm{~min}$, $\left.120^{\circ} \mathrm{C}\right)$ EWF specimens

surfaces. The amount of specific non-EWF $\beta w_{\mathrm{p}}$, however, decreased after annealing, which is attributed to a reduction of the energy dissipated by plastic deformation in the outer process zone. The tensile tests results for the as received and annealed dumbbell specimens support this observation. Although the EWF results show a clear trend and can be used in a qualitative manner, a direct quantitative translation of the EWF results to the toughness of composites is difficult. The toughness of composites not only depends on the polymer properties, but also on for example the fibrematrix adhesion and fibre distribution near the crack interface. Moreover, the properties of the polymer depend strongly on its thermal history. The tested annealed PPS film cannot be readily compared to the PPS in tape placed composites in terms of crystalline morphology and degree of crystallinity. Nevertheless, the results support the earlier experimental work concerning the fracture toughness of UD reinforced carbon-PPS tapes welded (using laser assisted tape placement equipment) onto carbon fabric reinforced laminates. ${ }^{4}$ There, the fracture toughness of the weld interface was found to decrease significantly upon annealing, which was mainly attributed to a decrease in the amount of plastic work during fracture.

\section{Conclusions}

The present work investigated the crystallisation and fracture toughness of PPS under tape placement conditions. A new fast scanning calorimeter from Mettler-Toledo (the Flash DSC 1) was successfully applied to investigate the critical (quench) rate. The PPS was found to be unable to crystallise when subjected to cooling rates in excess of $20^{\circ} \mathrm{C} \mathrm{s}^{-1}$ under quiescent conditions. As the cooling rates observed during in situ tape placement can be significantly higher, the PPS in such composites is anticipated to have an amorphous morphology. Consequently, the final product properties, such as chemical resistance or thermal stability, can differ from conventionally and slowly manufactured components. Clearly, the introduction of these new manufacturing methods, involving high heating and cooling rates, calls for an improved understanding of polymer crystallisation and its resulting properties.

The effect of crystallinity on the tensile behaviour and fracture toughness, through an EWF approach, was

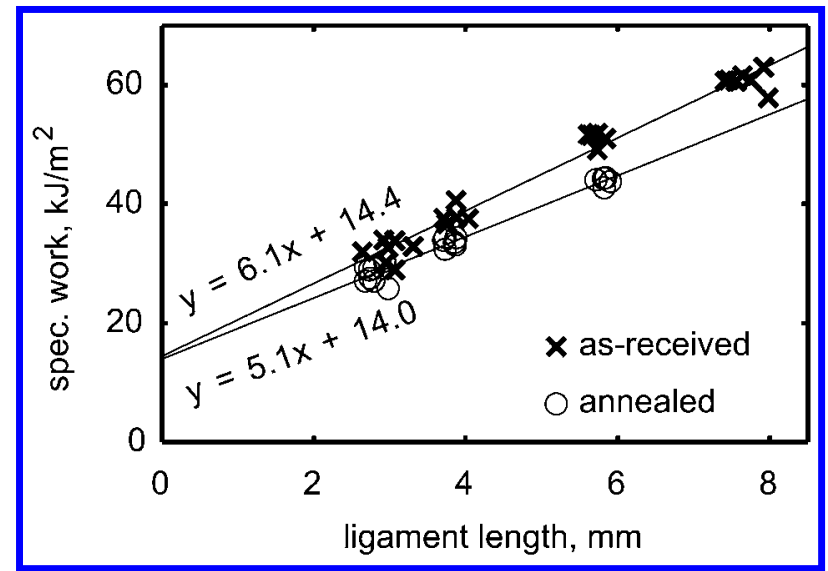

9 Specific work of fracture for as received and annealed (15 min, $120^{\circ} \mathrm{C}$ ) PPS film specimens

investigated experimentally for PPS film. The tests were performed on as received (low crystallinity) as well as annealed film specimens. The as received tensile specimens showed extensive plastic deformation prior to fracture, while the annealed specimens showed a more brittle fracture behaviour. Similarly, the EWF experiments demonstrated that the amount of plastic work spent during fracture decreases after an annealing procedure. The experimental results show that the tape placement of PPS based composites results in favourable fracture properties. Nevertheless, for practical application other properties, such as chemical resistance or strength and stiffness should also be taken into account. Additional research is therefore required to understand the effect of high heating and cooling rates on the properties of PPS and its composites.

\section{Acknowledgement}

The authors like to acknowledge the contributions of the following members of the thermal analysis department of DSM Resolve: Wil van Eijk and Asifur Rahman.

\section{References}

1. R. Schledjewski: 'Thermoplastic tape placement - in situ consolidation is reachable', Plast., Rubber Compos., 2009, 38, (9-10), 379-386.

2. E. P. Beyeler and S. I. Güçeri: 'Thermal analysis of laser-assisted thermoplastic-matrix composite tape consolidation', J. Heat Transfer, 1988, 110, (2), 424-430.

3. F. O. Sonmez and H. T. Hahn: 'Modeling of heat transfer and crystallisation in thermoplastic composite tape placement process', J. Thermoplast. Compos. Mater., 1997, 10, (3), 198-240.

4. W. J. B. Grouve, L. L. Warnet, B. Rietman and R. Akkerman: 'On the weld strength of in situ tape placed reinforcements on weave reinforced structures', Composites: Part A, 2012, 43, 1530-1536.

5. K. Ravindranath and J. P. Jog: 'Polymer crystallisation kinetics: poly(ethylene terephthalate) and poly(phenylene sulfide)', J. Appl. Polym. Sci., 1993, 49, (8), 1395-1403.

6. C. Auer, G. Kalinka, T. Krause and G. Hinrichsen: 'Crystallisation kinetics of pure and fiber-reinforced poly(phenylene sulfide)', $J$. Appl. Polym. Sci., 1994, 51, (3), 407-413.

7. C. Silvestre, E. Di Pace, R. Napolitano, B. Pirozzi and G. Cesario: 'Crystallisation, morphology, and thermal behavior of poly(pphenylene sulfide)', J. Polym. Sci., Part B: Polym. Phys., 2001, 39, (4), 415-424.

8. L. C. Lopez and G. L. Wilkes: 'Non-isothermal crystallisation kinetics of poly(p-phenylene sulphide)', Polymer, 1989, 30, (5), $882-887$.

9. L. I. Minkova and P. L. Magagnini: 'Non-isothermal crystallisation kinetics of poly(phenylene sulfide)/vectra-B blends', Polymer, 1995, 36, (10), 2059-2063. 
10. L. C. Lopez and G. L. Wilkes: 'Crystallisation kinetics of poly(pphenylene sulfide): effect of molecular weight', J. Macromol. Sci. Rev. Macromol. Chem. Phys., 1989, C29, 83-151.

11. P. Cebe: 'Review of recent developments in poly(phenylene sulphide)', Polym. Polym. Compos., 1995, 3, (4), 239-266.

12. J. E. Spruiell and C. J. Janke: 'A review of the measurement and development of crystallinity and its relation to properties in neat poly(phenylene sulfide) and its fiber reinforced composites', Technical report, Oak Ridge National Laboratory, 2004.

13. P. Davies, M. L. Benzeggagh and F. X. de Charentenay: 'Delamination behavior of carbon fiber reinforced PPS', SAMPE Q., 1987, 32, 134-146.

14. N. Nishihata, T. Koizumi, Y. Ichikawa and T. Katto: 'Plane strain fracture toughness of polyphenylene sulfide', Polym. Eng. Sci., 1998, 38, (3), 403-408.

15. Mettler-Toledo website: http://www.mt.com (accessed 23 February 2012).

16. V. Mathot, M. Pyda, T. Pijpers, G. Vanden Poel, E. van de Kerkhof, S. van Herwaarden, F. van Herwaarden and A. Leenaers: 'The Flash DSC 1, a power compensation twin-type, chip-based fast scanning calorimeter (FSC): First findings on polymers', Thermochim. Acta, 2011, 522, (1-2), 36-45.

17. S. van Herwaarden, E. Iervolino, F. van Herwaarden, T. Wijffels, A. Leenaers and V. Mathot: 'Design, performance and analysis of thermal lag of the UFS1 twin-calorimeter chip for fast scanning calorimetry using the Mettler-Toledo Flash DSC 1', Thermochim. Acta, 2011, 522, (1-2), 46-52.

18. E. Iervolino, A. W. van Herwaarden, F. G. van Herwaarden, E. van de Kerkhof, P. P. W. van Grinsven, A. C. H. I. Leenaers, V. B. F. Mathot and P. M. Sarro: 'Temperature calibration and electrical characterization of the differential scanning calorimeter chip UFS1 for the Mettler-Toledo Flash DSC 1, Thermochim. Acta, 2011, 522, (1-2), 53-59.
19. G. Vanden Poel: 'Performance and calibration of the Flash DSC 1, a new, MEMS-based fast scanning calorimeter', J. Therm. Anal. Calorim., 2012, 110, (3), 1533-1546.

20. K. B. Broberg: 'On stable crack growth', J. Mech. Phys. Solids, 1975, 23, (3), 215-237.

21. S. Hashemi: 'Effect of temperature on fracture toughness on an amorphous poly(ether-ether ketone) film using essential work of fracture analysis', Polym. Test., 2003, 22, 589-599.

22. B. Cotterell and J. K. Reddel: 'The essential work of plane stress ductile fracture', Int. J. Fract., 1977, 13, (3), 267-277.

23. Y. W. Mai and B. Cotterell: 'On the essential work of ductile fracture in polymers', Int. J. Fract., 1986, 32, (2), 105-125.

24. Y. W. Mai, S. C. Wong and X. H. Chen: 'Application of fracture mechanics for characterization of toughness of polymer blends', Polym. Blends, 2000, 2, 17-58.

25. T. Bárány, T. Czigány and J. Karger-Kocsis: 'Application of the essential work of fracture (EWF) concept for polymers, related blends and composites: a review', Prog. Polym. Sci. (Oxford), 2010, 35, (10), 1257-1287.

26. J. J. Casellas, P. M. Frontini and J. M. Carella: 'Fracture characterization of low-density polyethylenes by the essential work of fracture: changes induced by thermal treatments and testing temperature', J. Appl. Polym. Sci., 1999, 74, (4), 781-796.

27. R. Lv, W. Xu, B. Na and J. Yan: 'Correlation of mechanical behaviors with crystalline phase and related cavitation in isotactic polypropylene', J. Appl. Polym. Sci., 2008, 108, (5), 3185-3190.

28. E. Clutton: 'Essential work of fracture', in 'Fracture mechanics testing methods for polymers, adhesives and composites', Vol. 28 (European Structural Integrity Society), 177-195; 2001, Oxford, Elsevier.

29. R.-C. Zhang, Y. Xu, K. Cheng and Z.-M. Li: 'Shear-induced crystallisation of poly(phenylene sulfide)', Polymer, 2008, 45, 2604 2616. 